\title{
Review
}

Klára Ščupáková, Benjamin Balluff, Caitlin Tressler, Tobi Adelaja, Ron M.A. Heeren*, Kristine Glunde and Gökhan Ertaylan

\section{Cellular resolution in clinical MALDI mass spectrometry imaging: the latest advancements and current challenges}

https://doi.org/10.1515/cclm-2019-0858

Received August 14, 2019; accepted October 7, 2019; previously published online October 30, 2019

\begin{abstract}
Mass spectrometry (MS) is the workhorse of metabolomics, proteomics and lipidomics. Mass spectrometry imaging (MSI), its extension to spatially resolved analysis of tissues, is a powerful tool for visualizing molecular information within the histological context of tissue. This review summarizes recent developments in MSI and highlights current challenges that remain to achieve molecular imaging at the cellular level of clinical specimens. We focus on matrix-assisted laser desorption/ ionization (MALDI)-MSI. We discuss the current status of each of the analysis steps and remaining challenges to reach the desired level of cellular imaging. Currently, analyte delocalization and degradation, matrix crystal size, laser focus restrictions and detector sensitivity are factors that are limiting spatial resolution. New sample preparation devices and laser optic systems are being
\end{abstract}

\footnotetext{
*Corresponding author: Ron M.A. Heeren, Maastricht MultiModal Molecular Imaging Institute (M4I), University of Maastricht, Maastricht, The Netherlands, E-mail: r.heeren@maastrichtuniversity.nl. https://orcid.org/00000002-6533-7179

Klára Ščupáková and Benjamin Balluff: Maastricht MultiModal Molecular Imaging Institute (M4I), University of Maastricht, Maastricht, The Netherlands. https://orcid.org/0000-0002-97263565 (K. Ščupáková).

Caitlin Tressler and Tobi Adelaja: Russell H. Morgan Department of Radiology and Radiological Science, Division of Cancer Imaging Research, The Johns Hopkins University School of Medicine, Baltimore, MD, USA

Kristine Glunde: Russell H. Morgan Department of Radiology and Radiological Science, Division of Cancer Imaging Research, The Johns Hopkins University School of Medicine, Baltimore, MD, USA; and The Sidney Kimmel Comprehensive Cancer Center, The Johns Hopkins University School of Medicine, Baltimore, MD, USA Gökhan Ertaylan: Unit Health, Flemish Institute for Technological Research (VITO), Mol, Belgium
}

developed to push the boundaries of these limitations. Furthermore, we review the processing of cellular MSI data and images, and the systematic integration of these data in the light of available algorithms and databases. We discuss roadblocks in the data analysis pipeline and show how technology from other fields can be used to overcome these. Finally, we conclude with curative and community efforts that are needed to enable contextualization of the information obtained.

Keywords: data analysis; data integration and interpretation; histopathology; mass spectrometry imaging; molecular analysis; spatial resolution.

\section{Introduction}

Cells are biological, structural and functional units of life. The ability of cells to organize themselves into highly structured, complex tissues allows for the functioning of organs and organisms. To this end, different types of cells can exist harmoniously, next to each other, performing different functions. Cellular metabolism involves a set of complex and highly coordinated biochemical reactions that convert or use energy to fuel biological processes including development, proliferation, differentiation and responses to stimuli [1]. Each cell is dynamic and communicates with neighboring and distant cells through complex physiological signaling networks of cytokines, hormones and eicosanoids on target receptors [2, 3]. Cells control these biomolecules to meet bioenergetic demands, adjust to the surrounding microenvironment and respond to environmental stimuli. Both physiologically normal and pathological tissues display typical molecular characteristics, including activated and deactivated pathways, changes in metabolite concentrations, differences in lipid and protein profiles and differential gene expression, all of 
which lead to unique molecular (as well as phenotypical) profiles for individual cells [4].

The identification of disease-specific molecular profiles requires an understanding of how biomolecules are altered in both the diseased tissue and the microenvironment surrounding it. Ideally, this would be achieved through an approach that accurately measures biomolecular features in a high-throughput and spatially resolved manner. To be able to obtain molecular information at the cellular level from tissue specimens, the spatial resolution of a given molecular imaging technique has to be at a minimum of the size of the cells being investigated. For human cells, the diameter of a cell ranges from $5 \mu \mathrm{m}$ (sperm cell) to $100 \mu \mathrm{m}$ (adipocyte) or even as large as $150 \mu \mathrm{m}$ (ovum) [5, 6], however, on average cell diameters are about 10-20 $\mu \mathrm{m}$ [7]. In some diseases, the average size of the affected cells has been documented to change. One such example is cancer where it is common that tumor cells become larger than their respective normal cells [8]. In many cases, cells of different sizes are mixed. For example, tumor cells are often surrounded by much smaller infiltrating lymphocytes [9]. The minimum spatial resolution needed is thus determined by the smallest cell or distance between cells (Figure 1).

Currently, different imaging methods are applied to obtain a partial picture of a given cell's molecular composition. Immunohistochemical or fluorescent DNA probes, and various other molecular labeling techniques can give insight into specific, spatially resolved information about protein expression and genetic features $[10,11]$. However, pitfalls in antibody clone selection, antibody consumable costs, and improper tissue stewardship for recurrent antibody staining are challenges to widespread clinical implementation [12].

Mass spectrometry imaging (MSI) is a promising technology as it uses, contrary to labeling techniques, the chemical sensitivity and specificity of MS for the spatial analysis of biological tissue sections. MSI, unlike targeted imaging (e.g. immunohistochemistry), can detect hundreds of molecules simultaneously in a single experiment with no prior knowledge required on the analytes present. As a result, this technology has become a useful tool for mapping the molecular composition directly from tissue while preserving spatial morphology [13-16]. MSI has gained interest in biomedical research for the investigation of diseased tissues in oncology [17, 18], neurology [19, 20] and endocrinology [21, 22]. A few examples in these areas, which have already utilized MSI technology, have provided molecular classifiers with diagnostic potential in cancer, and have advanced the molecular understanding of diabetic Langerhans islands [23]. Pathology is another field that is beginning to embrace MSI technology, which is a result of similar workflows in MSI and immunohistochemistry, as well as the incorporation of histological information into MSI workflows. One of the primary limitations of MSI, however, is that of limited spatial resolution, which is currently one of the major obstacles preventing the implementation of MSI technology in the anatomic pathology laboratory.

In this review, we will discuss recent technological advances in MSI, in particular as they relate to spatial resolution. Furthermore, we will outline challenges and technological gaps that currently limit the possibility of achieving molecular imaging by MSI of clinical samples at the cellular level.
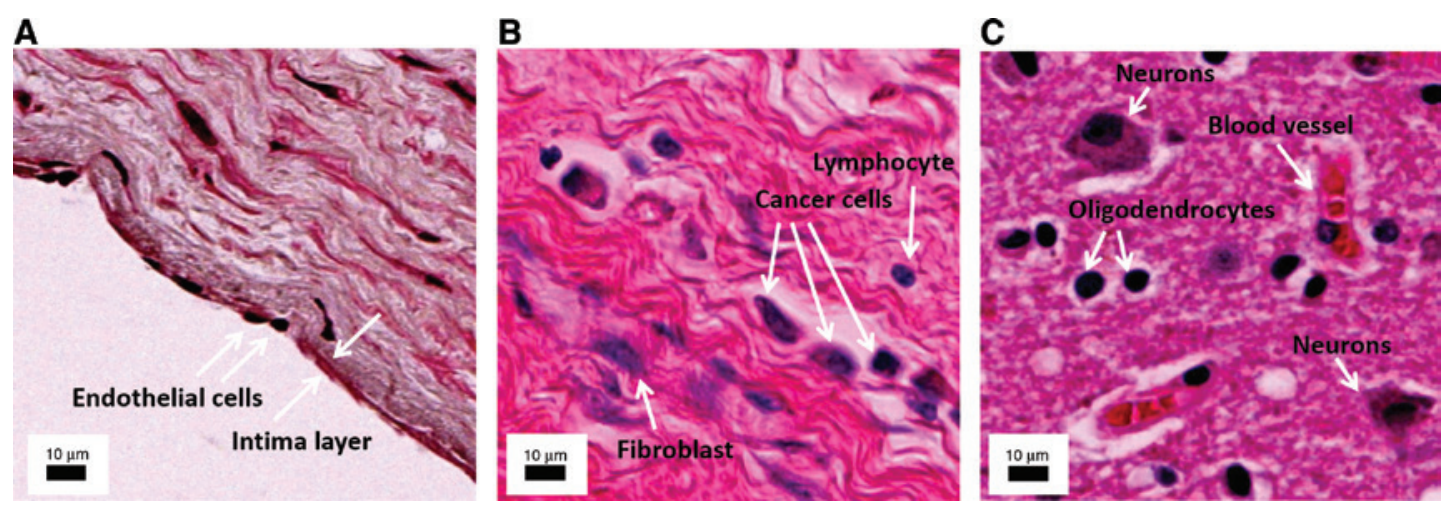

Figure 1: The need for single cell MSI.

The necessity for high resolution MSI becomes evident in these microscopic images of different clinical cases. (A) Human artery, arrows indicate one cell thick intima layer consisting of endothelial cells. (B) Human lobular breast carcinoma, arrows indicate cancer cells, a fibroblast, and a lymphocyte. (C) Human Alzheimer's brain, arrows show the lymphocytes, an astrocyte, an oligodendrocyte, and a blood vessel. The annotations were performed to the best of our knowledge, however, additional cell-specific staining is necessary to confirm cell identities. The scale bar in all images is $10 \mu \mathrm{m}$. 


\section{MSI techniques}

Several MSI technologies exist, encompassing a variety of ion sources and mass analyzers suitable for diverse molecular analysis, with each source-analyzer combination enabling different mass and spatial resolutions. Hence in MSI, the selection of appropriate technology suitable for the purpose at hand is essential for achieving the desired resolution and coverage.

Secondary ion mass spectrometry (SIMS) was the first MS technique to be applied to imaging in the $1960 \mathrm{~s}$ [24]. While SIMS offers spatial resolution at the nanometer scale, it utilizes a primary ion beam, which results in a high fragmentation yield, making it more appropriate for elemental and low molecular weight analysis in tissue samples, such as metabolites and small molecule drugs. An exceptional study, presented by Angelo et al. [25], has used lanthanide labeled antibodies and SIMS to obtain single cell protein distribution from human breast carcinoma. Second to be introduced in the late 1990s [26], was matrix-assisted laser desorption/ionization (MALDI) technology which offers softer ionization and thus enables the analysis of larger biomolecules, such as proteins without the need for expensive isotopic labeling. Since the introduction of MALDI-MSI, the field of MSI has begun to grow exponentially with many other new technologies being introduced recently, which include ambient technologies such as desorption electrospray ionization (DESI), and liquid extraction surface analysis (LESA). Additional laser technologies have been developed, such as laser ablation electrospray ionization (LAESI) or laser ablation inductively coupled plasma mass spectrometry (LA-ICP-MS). Detailed reviews of each of these MSI technologies can be found in the referenced publications [14, 16, 27]. Each of these technologies offers different properties in terms of spatial resolution, chemical scope, and speed. Owing to the flexible mass range, soft ionization, and especially advancements in speed and spatial resolution, MALDI is currently the most commonly used MSI tool in clinical research. For this reason, we will keep the focus of this review on MALDI-MSI towards single cell analysis.

\section{Current state of single cell MALDI-MSI}

In recent years, a few studies have reported high spatial resolution MALDI-MSI reaching single cell scale. For instance, Kompauer et al. [28] have shown advancements in instrumentation allowing for measurements at lateral resolution of $1.4 \mu \mathrm{m}$ per pixel. In their study, they successfully demonstrated that high spatial resolution MALDIMSI enabled mapping of subcellular lipid, metabolite and peptide distributions in single-cellular Paramecium caudatum and multicellular Rotifera organisms. Another study presented 3D single cell MALDI-MSI of fertilized zebrafish embryo, which was performed to map lipid distributions during the embryonic development [29]. Furthermore, Lee and co-workers studied maize leaf at the desired single cell resolution using MALDI-MSI [30-32] and revealed modifications in the distribution of thylakoid membrane lipids in individual cells.

These studies highlight that the physical requirements of MSI instrumentation and sample preparation are already able to reach single cell resolution. Even though commercial instruments that allow for single cell resolution exist [33-35], to date, the vast majority of high spatial resolution MALDI-MSI studies have been performed using in-house customized instrument configurations. Moreover, most of the studies have focused on developmental and biological research questions rather than clinicallyoriented research. The reasons why single cell MALDI-MSI is not yet the default strategy for clinical investigations are as follows: (a) not all clinical cases require single cell resolution, (b) sample preparation of clinical samples has many steps that could cause analyte delocalization which would hamper high spatial resolution, (c) increase in spatial resolution also results in loss of sensitivity and hence in loss of molecular information, (d) the acquisition time is significantly longer in high spatial resolution MSI, and finally (f) the data size increases and makes data handling, processing, integration and storage more difficult.

In this review, we will expose and discuss these challenges that prevent the routine use of single cell MALDIMSI for investigating clinical specimens. Subsequently, we underline ongoing developments that are important for the MALDI-MSI community, including advances in digital image analysis and management, and emphasize future directions that will increase the clinical impact of MSI.

\section{Recent developments and existing challenges in clinical cellular MALDI-MSI}

Typical MALDI-MSI workflows consist of tissue harvesting, tissue preservation, tissue sectioning, sample preparation, matrix application, MSI data acquisition, post-MSI histopathological staining, image co-registration, identification of candidate masses of interest, pathway analysis, data 
integration and data interpretation. In this review, we will cover each of these steps, highlighting their importance, recent advancements, and gaps to be filled when considering high spatial resolution MALDI-MSI of clinical samples.

\section{Tissue/sample retrieval and preservation}

Critical to all biological investigation is tissue extraction and preservation [36]. It is essential to adhere to protocols that preserve tissue integrity and limit degradation and delocalization of biomolecules within tissue. MALDI-MSI is best achieved from fresh-frozen (FF) tissues. Several factors that can affect tissue quality have been in detailed in Chughtai and Heeren [14]. Typically, FF samples for MSI are stored at $-80{ }^{\circ} \mathrm{C}$, which offers stable conditions for about 1 year. Afterwards peptide/protein degradation has been observed to occur [37-39].

The second, traditional form of tissue preservation is formalin fixation and paraffin embedding (FFPE) of tissue specimens. One of the benefits of FFPE tissue is that it preserves histomorphological features and results in minimum antigen decay during long-term storage [40]. Hence, FFPE fixation has been the "gold standard" in surgical pathology. Furthermore, extensive libraries of FFPE tissue blocks exist in biobanks all around the world, offering a vast source of samples for clinically-oriented MSI analysis. However, paraffin, which is required for preservation and sectioning of formalin-fixed tissue, as well as the cross-linking of proteins caused by formaldehyde, hamper molecular desorption and ionization in MALDIMSI. In fact, any kind of chemical fixation of tissues can lead to modification of biomolecules of interest and hence is a suboptimal way of sample preservation. However, novel protocols have been developed in recent years [38, 41] to reverse these sample treatment steps and hence have enabled FFPE samples to be compatible with MSI.

Recent studies have proposed other fixatives as alternatives to FF or FFPE tissues [42, 43], but they have yet to be proven suitable substitutes that control for tissue preanalytical variables. The requirements for new fixatives suitable for both pathology and MSI are: preservation of histomorphological features, non-cross-linking, noncarcinogenic, and resulting in minimal antigen decay when tissue is archived long term (e.g. 10 years).

\section{Sample preparation}

Depending on the molecular class and tissue type of interest to be imaged, different sample preparation steps are necessary as illustrated in Figure 2. Recent reviews by Swales et al. [16] and Buchberger et al. [27] have detailed the necessary steps in MALDI-MSI sample preparation for targeting the desired molecular class.

The first step in sample preparation is tissue sectioning. As MSI is a surface analysis technique, all samples must be sectioned thinly, i.e. at 2-7 $\mu \mathrm{m}$ for FFPE and at 7-20 $\mu \mathrm{m}$ for FF tissue sections [14, 44]. Fresh-frozen tissue is less stable and more fragile than FFPE tissue, and thus results in more variation and more artefacts during sectioning than FFPE tissue sectioning. In the case of cryosectioning, temperature variations as well as the time interval between tissue sectioning and tissue mounting, can lead to molecular and, less commonly, morphological degradation of tissues [39, 44]. Also, some specimens are too small to be directly mounted onto the cryotome stage and further embedding in gelatin, agarose, carboxymethylcellulose [45] or optimal cutting temperature (OCT) compound [46-48] is required. This increases the possibility of further sample degradation or deformation. Recently, poly(N-[2-hydroxypropyl]methacrylamide), a new cutting medium that is liquid at freezing temperatures has been developed to overcome sample degradation and sectioning hurdles [49]. More intricate details on cryo-sectioning have been discussed elsewhere [14, 16, 36, 39, 44].

When preparing samples for analysis at cellular resolution, it is also important to realize that the observed diameter of each cell depends on the cutting plane and the orientation of a given cell in the tissue. This is most dramatically exemplified by neurons. The transverse cutting plane of a neuron can be as small as $4 \mu \mathrm{m}$ in a granule cell, whereas in the coronal or sagittal cutting planes, the diameter can be as large as $1 \mathrm{~m}[50,51]$. Therefore, section orientation may also be critical for the spatial resolution needed to image a particular tissue`s molecular information at the cellular level.

Next steps and complexity of sample preparation vary and depend on the type of tissue to be analyzed. For FF tissue, in some applications no sample preparation apart from matrix application is needed, while for FFPE tissue, a multi-step process is required, which usually involves deparaffinization, tissue rehydration and antigen retrieval. Enzymatic or additional chemical treatment may also be necessary depending on the molecular class to be analyzed. The last, but essential, step in MALDIMSI sample preparation is matrix application, which must be done regardless of any type of previous sample preparation. Each of the steps is a potential source of analyte delocalization or degradation. Delocalization is a phenomenon where molecules migrate/diffuse across and away from the tissue. The severity of delocalization 


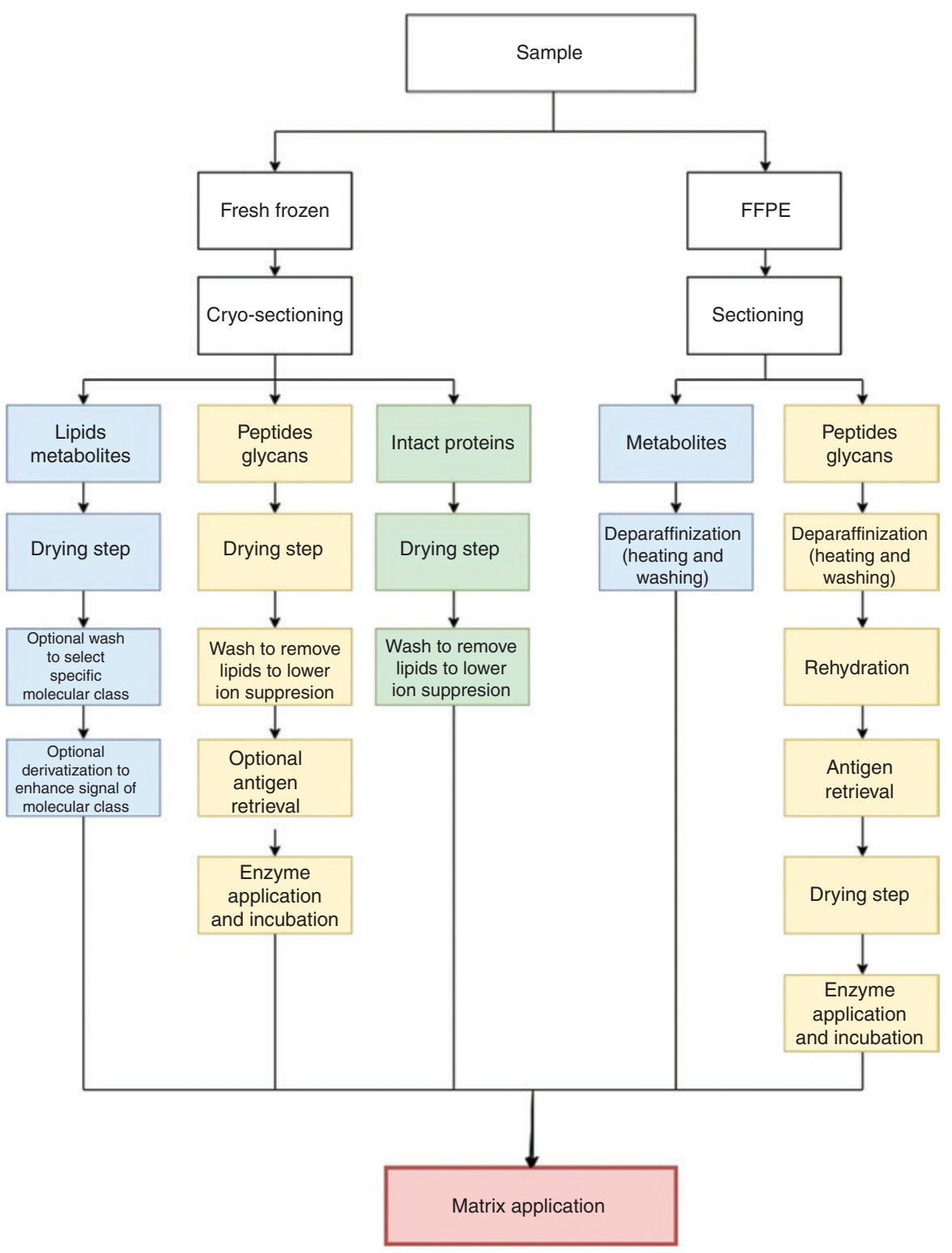

Figure 2: Flowchart of typical MALDI-MSI sample preparation steps. Depending on the type of sample preservation and molecular class of interest, different steps are necessary. FFPE, formalin-fixed paraffin-embedded.

is molecule-, sample- and protocol-dependent [52-55]. A representative MS image of the molecular delocalization of adenosine triphosphate (ATP) in a diffuse large B-cell lymphoma tissue is shown in Figure 3A.

The choice of matrix, solvent system, temperature and means of matrix application are all critical in MALDIMSI to ensure good extraction and subsequent ionization of the analyte of interest $[16,27,36]$. Furthermore, the way that matrix is applied - for example, through wet coating by a nebulizing sprayer (e.g. ${ }^{\text {TM} S p r a y e r ~[H T X ~ i m a g i n g], ~}$ Suncollect Sprayer [Sunchrom]) or dry coating (sublimation process e.g. Sublimator [HTX imaging], iMlayer ${ }^{\mathrm{TM}}$
[Shimadzu]) - affects the degree of potential delocalization (Figure 3B) and the obtained matrix crystal size [56-58]. Recently, Huizing et al. [52] have evaluated how desiccation prior to matrix application affects analyte delocalization. They report delocalization effects for various matrices and application devices, concluding that desiccation in a vacuum desiccator should be omitted to prevent water condensation, which could result in delocalization (Figure 3B).

Matrix crystal size is one of the most crucial factors that determines achievable cellular spatial resolution (Figure 4). Many efforts have been made to minimize crystal size and 
A Delocalization

No delocalization

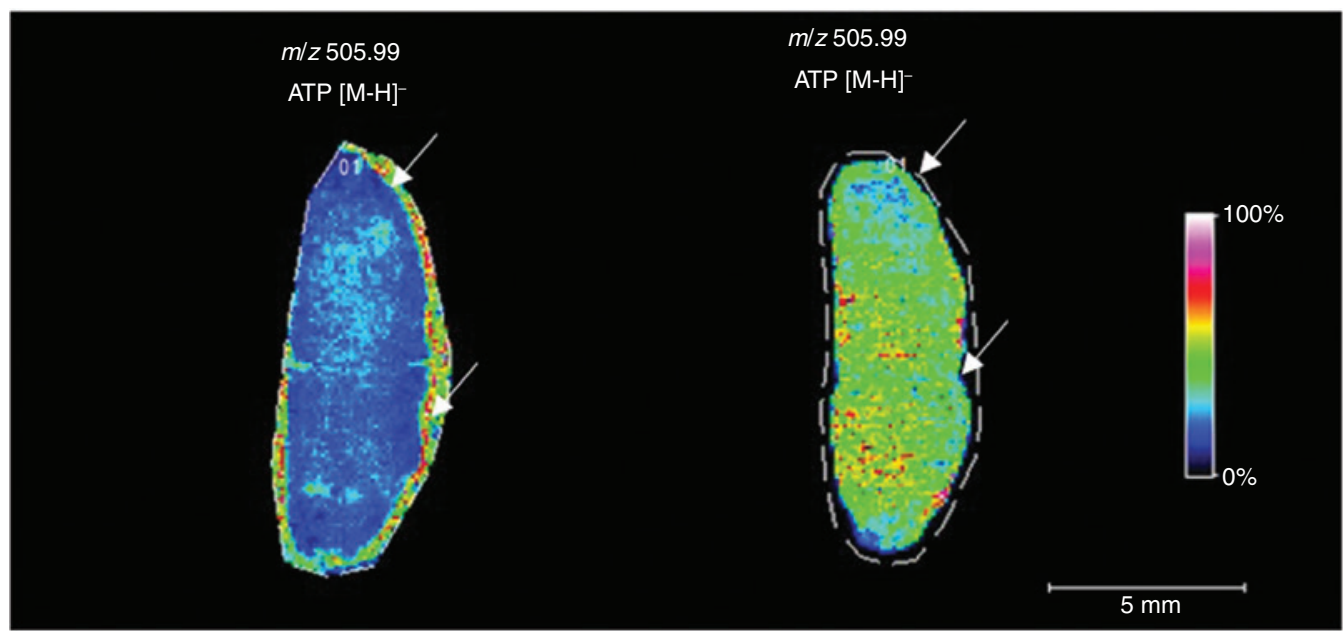

B

With desiccation step

Without desiccation step
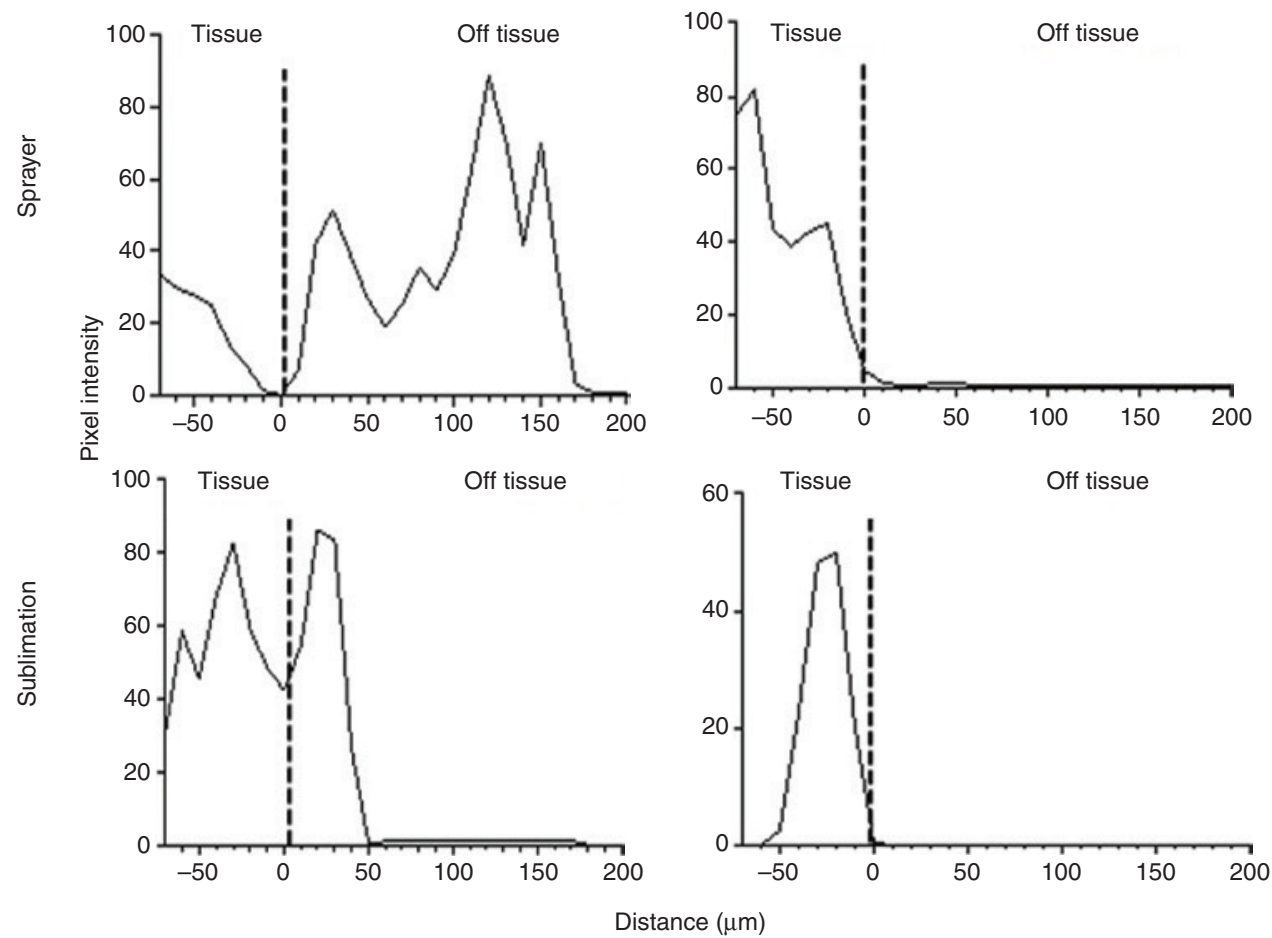

Figure 3: Effect of sample handling and matrix deposition on analyte delocalisation.

(A) MS image of ATP ( $m / z$ 505.99) in a diffuse large B-cell lymphoma tissue showing ATP delocalization. On the left, a large portion of the detected ATP is localized outside the tissue due to delocalization, whereas on the right, ATP is contained within the tissue. The white line indicates the area that was sampled by MALDI-MSI, whereas the arrows point to the border of the tissue. NEDC matrix was applied to both tissues with the same spraying method. For the left tissue, nitrogen gas was used for the drying step, whereas the right tissue was dried in a carrier box with silica gel. (B) Reprinted with permission from Huizing et al. [52] to demonstrate that certain sample preparation steps, in particular the desiccation step, as well as means of matrix deposition, have an effect on the severity of analyte delocalization. Line profile of intensity distribution of $m / z 808.5 \pm 0.1$ (identified as [PC(36:2) $\left.+\mathrm{Na}^{+}\right]$). This graph shows that depending on the sample preparation, $m / z$ 808.5 can be detected with high intensity up to $200 \mu \mathrm{m}$ away from the border of the tissue, demonstrating a strong delocalization effect. Data shown were obtained using norharmane matrix. The dotted line indicates the edge of the tissue.

decrease crystal size heterogeneity during matrix application. Current commercial sublimation and spraying systems are nowadays - depending on the matrix used - able to achieve crystal sizes in the range of 1-30 $\mu \mathrm{m}$, with sublimation generally able to reach even smaller crystal sizes $[56,59$, 60]. Further developments, such as electrospray deposition 
or matrix-free electron-directed soft ionization continue to push the limits toward better spatial resolution [57, 61].

\section{The need for enhanced laser systems and sensitivity}

As described above, the achievable resolution in a MALDIMSI experiment depends on many factors during sample preparation, including the average matrix crystal size and delocalization effects during sample preparation. A third factor that determines the achievable lateral resolution is the diameter of the laser spot size of the mass spectrometer $[62,63]$ (Figure 4). Throughout the last decade, the laser diameter in mass spectrometers for MSI has been reduced from $100 \mu \mathrm{m}$ to below $10 \mu \mathrm{m}$ in 2011, below $5 \mu \mathrm{m}$ in 201, and below $1.5 \mu \mathrm{m}$ in 2017 [28, 64, 65]. Unfortunately, as the irradiated area becomes smaller the ion yields decline as well [66] (Figure 5A). This requires new ultra-sensitive detectors or methods that increase ion yields. Efforts have been made to maintain the optimal focus condition all over the sample by pixel-to-pixel height adaption [67] or to boost the postdesorption ionization process through additional lasers intercepting the particle plume [68] (Figure 5B). Furthermore, next generation detectors, such as the Medipix4 are also being developed to overcome these physical limitations of high spatial resolution [69-71].

\section{Data handling and storage}

While single cell, spatially resolved MALDI-MSI data holds the promise of comprehensively elucidating the molecular underpinnings of cellular functioning within the tissue context, it will inevitably lead to extraordinarily large datasets. Performing MSI at single cell resolution emphasizes the need for efficient and fast processing algorithms and smart storage solutions beyond current capabilities. While current technological advancements allow for data acquisition at single cell resolution, it is not routine practice to acquire whole specimens at that resolution. Nowadays, it is common to perform a whole specimen rapid screening at low resolution to identify regions of interest and reanalyze these at high spatial resolution. As illustrated in Figure 6, data set sizes will exponentially reach terabyte level if the spatial resolution routinely achieved moves from supercellular to cellular and subcellular scale for whole specimen imaging. In addition, the gain in resolution also prolongs the acquisition time in the same way as it increases data size. Recently, ultra-fast MSI instrumentation was developed for compensating the elevated acquisition time of high resolution MSI [72-75]. This is expected to lead, in the near future, to additional investments in fast and efficient technology development as well as data reduction and storage solutions.
A

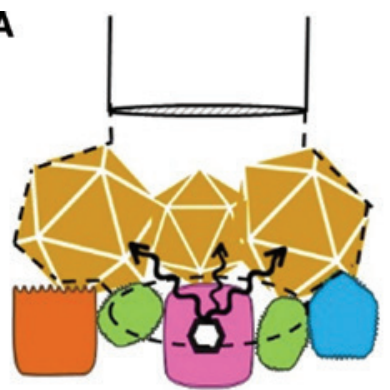

C

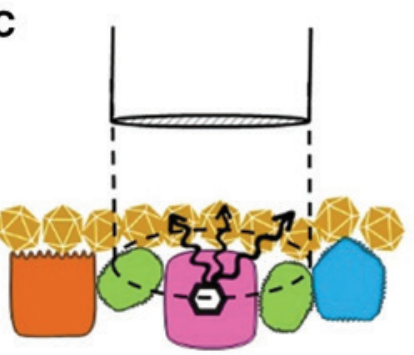

B

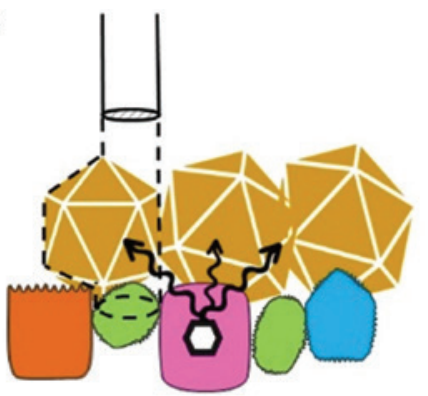

D

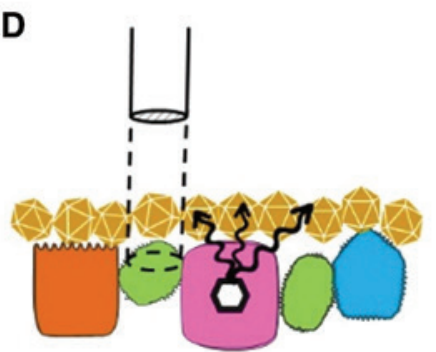

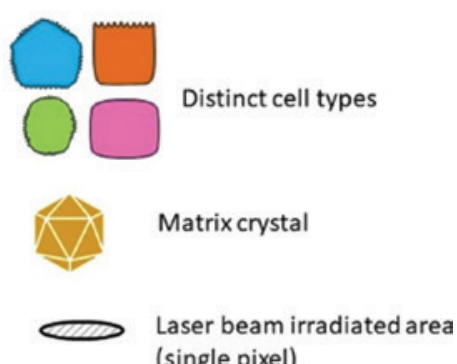

(single pixel)

:-ンi Extraction field for

single pixel

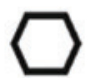

Molecule

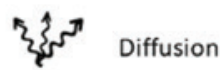

$10 \mu \mathrm{m} \longmapsto$

Figure 4: The principle of MALDI-MSI in the context of spatial resolution, analyte delocalization, and dimensions of cells, matrix crystals, and laser beam focus.

(A) In this case, matrix crystal size and laser diameter are both bigger than the average cell size and therefore prevent MSI at cellular resolution. (B) Here, the matrix crystal size is the limiting factor. (C) Here, the laser diameter is bigger than the matrix crystal size and the cell size, hence defining the resolution limit. (D) In this case, matrix and laser allow for resolving single cells. A third limiting factor is diffusion of molecules, which can happen during sample preparation, causing delocalization. 
A

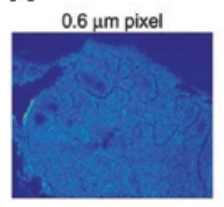

2.4 um pixel

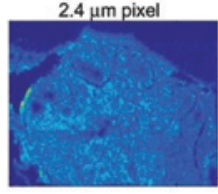

5 um pixel

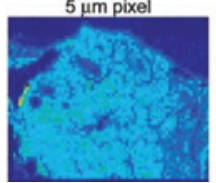

B

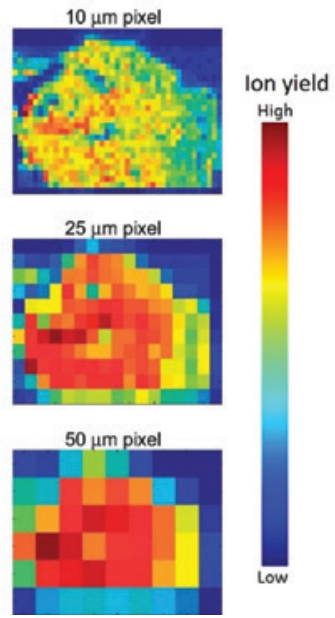

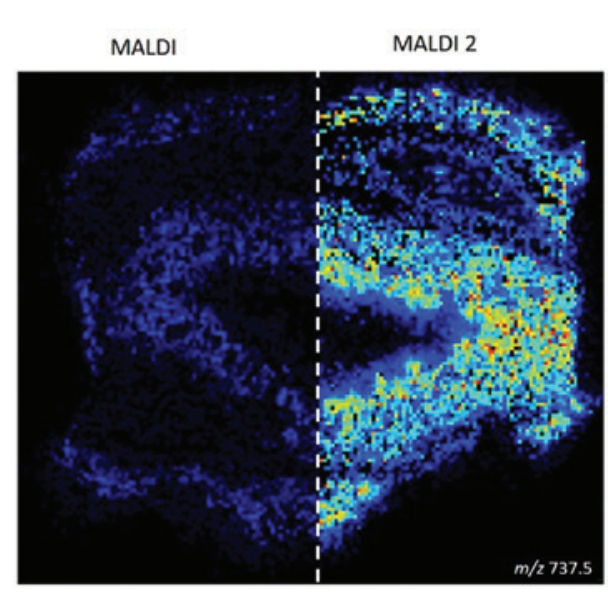

Figure 5: The effect of spatial resolution on ion yield.

(A) The same specimens analyzed at 6 different pixel resolutions showing the drop-in ion yield as the pixel size gets smaller. Reprinted with permission from McDonnell and Heeren [66]. (B) Mouse intestine tissue analyzed on the left by regular MALDI-MSI and on the right by post-desorption ionization aided MALDI-MSI, also referred to as MALDI 2 . The MS image at $\mathrm{m} / \mathrm{z} 737.5$ shows the increase in ion generation capabilities of MALDI 2, where a secondary laser is introduced. This data was kindly provided by Janssen Pharmaceutica NV.

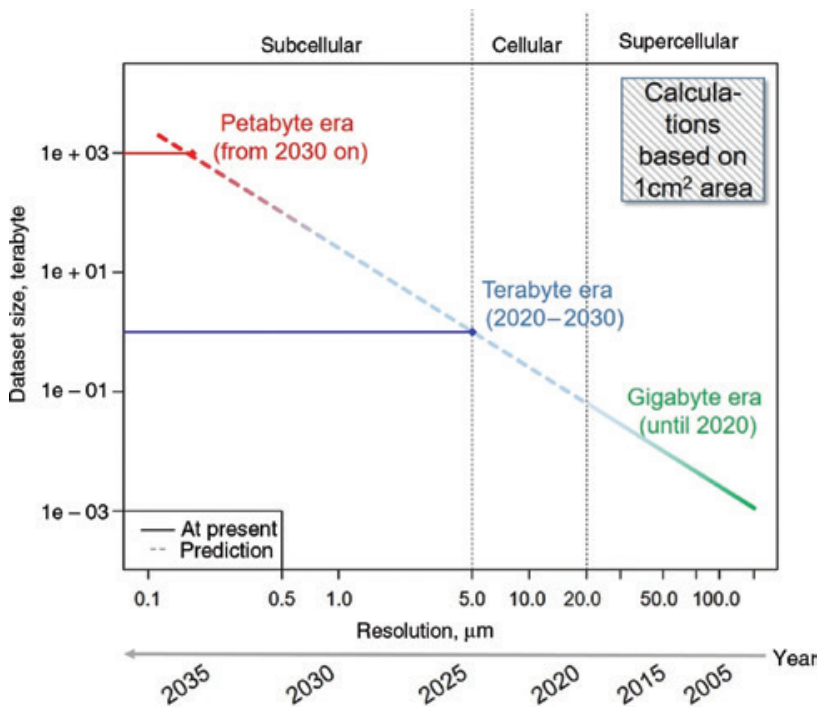

Figure 6: Prediction of data size growth for routine MALDI-MSI measurements in the next decade when spatial resolution reaches submicron levels.

All axes are log-scaled.

\section{Combining MSI and optical microscopy}

In the previous section, we have summarized the progress in MALDI-MSI towards cellular spatial resolution for analyzing clinical samples. Currently, samples are analyzed clinically using histopathological staining, immunohistochemistry and optical microscopy. These technologies are compatible with MSI, where sections can be imaged using MALDI-MSI and then stained using traditional histopathology techniques.

It is current practice in the MSI community to hematoxylin and eosin (H\&E) stain the sample post-MSI, or to stain a consecutive section, which can subsequently be co-registered to the MSI dataset and annotated for interpretation of the MSI data in the histopathological context. As with any data manipulation, an error is introduced by the limited precision of co-registration. Until now, this error has been smaller than the average pixel size, and has therefore been neglected [76]. As the spatial resolution of MSI datasets increases, this error becomes more significant. More sophisticated co-registration strategies, such as elastic warping $[77,78]$, will have to be applied to refine the co-registration and minimize the error.

Once precisely co-registered, it is possible to analyze the obtained MALDI-MSI data in a detailed spatio-anatomical context provided by histology overlay. MALDI-MSI and histology can be considered complementary analytical tools for examining tissue organization and function $[15,64]$. However, the current difference in spatial resolution of MALDI-MSI and histology images complicates the visual interpretation of these combined data.

\section{Computationally enhanced spatial resolution in MALDI-MSI}

Currently, the gold standard in the clinical setting is histology and immunohistochemistry, detected by optical 
microscopy. Contrary to MALDI-MSI, today's high-resolution optical microscopy offers superior spatial resolution, on the order of $100 \mathrm{~nm}$ [79], providing rich anatomical information and fine structural details. Several mathematical approaches to integrate these two imaging modalities have been developed to enhance the spatial resolution of MALDI-MSI beyond its experimental limits. The first method proposed by Alexandrov et al. [80] in 2011 improved the spatial resolution of a segmentation map by upscaling and smoothing the segment's boundaries while preserving fine details [17, 81-83]. A few years later, in 2015, image fusion by Van de Plas et al. [84] was introduced. Image fusion is based on linear regression analysis and, besides super-resolution, it also offers prediction of analyte distribution within an unmeasured sample based on combined MSI and histology patterns that the algorithm has learned from previously measured, similar samples. Recently, a patch-based super-resolution algorithm was presented by Ščupáková et al. [85], providing an alternative method to generate histology-driven super-resolution MSI images. Using these algorithms, the resolution of MSI can be simulated down to $0.5-1.0 \mu \mathrm{m}$ (Figure 7). In practice, these algorithms could be used where high spatial resolution MSI cannot be achieved due to time, cost, instrumentation or sample availability constraints. Caution must be exercised when performing statistical tests within such upscaled datasets, as the new pixels violate the assumption of independence (spatial autocorrelation) which can cause these tests to fail [86]. Despite this fact, these super-resolution approaches may also help with the next step of integrating MALDI-MSI with digital pathology, where fine structural details from histology can be fused with the rich molecular detail provided by MALDI-MSI at submicron spatial resolution.

\section{MSI and digital pathology}

In surgical pathology diagnoses are often made by conventional $\mathrm{H} \& \mathrm{E}$ and microscopy due to surgical time restrictions [87]. This approach has remained the foundation of modern pathology and diagnostic medicine for over a century [88]. Even now that technological advancements of various "omics" platforms slowly reach diagnostic maturity, conventional microscopy remains one of the most versatile and most commonly used diagnostic tools. In histological evaluations, important region-to-region, single cell level, and spatial level information that has significant implications for diagnostic purposes and/ or treatment decisions is preserved. A limitation of conventional microscopy in diagnosis is skill and training

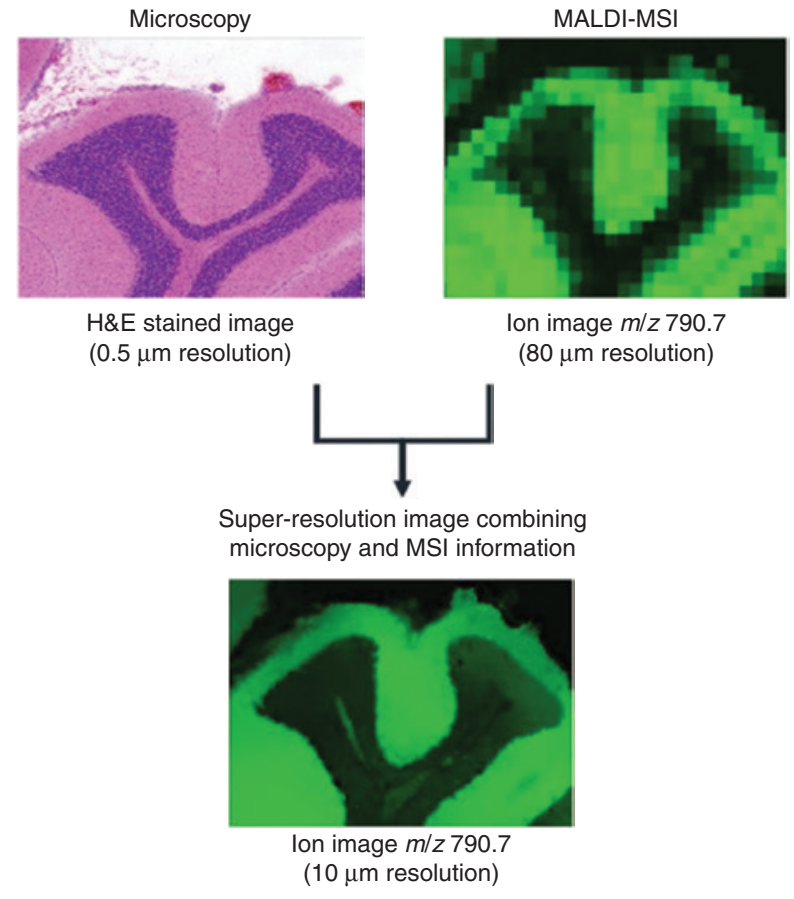

Figure 7: Concept of super-resolution applied to MSI and histology to increase the spatial resolution of MS images.

A high resolution $-0.5 \mu \mathrm{m}$ - histology image of mouse brain is integrated with a low resolution - $80 \mu \mathrm{m}$ - MS image at $m / z 790.7$ acquired from the same tissue section. Using the information from the two image sources, the super-resolution algorithm is able to predict the new distribution of $m / z 790.7$ at $10 \mu \mathrm{m}$ resolution. Figure based on the procedure proposed by Ščupáková et al. [85].

of the observer, which may introduce considerable interobserver variability depending on the specimen and the diagnosis $[89,90]$.

In the last decade, the digital pathology (or Precision Pathology) field [91] has emerged as a discipline trying to capture all information contained within histologystained tissue samples measured automatically with a slide scanner, followed by saving it as a digital image (whole slide image, WSI) for downstream annotation and analysis [92]. It has recently become possible to analyze WSIs using digital image analysis based on machine learning algorithms, as a large number of WSIs have been collected, annotated and accumulated over time. Digital pathology image analysis has been applied to assist tasks including annotation and diagnosis to identify and segment tumor regions in breast cancer [93], automatically score estrogen receptor immunohistochemistry for classification of breast cancer [94], or to quantify tumor budding in colorectal cancer [95]. Furthermore, platforms such as the Pathology Image Exchange have been created to allow pathological data to be shared online while maintaining patient privacy [96]. 
Digital pathology image analysis often uses general image recognition technology (similar to software used for facial recognition) as a basis. Furthermore, digital pathology implements domain specific adaptations as digital pathological images and tasks have unique characteristics and thus require advanced processing techniques. Since 2012, when the overwhelming success of the team using deep learning algorithms at ImageNet Large Scale Visual Recognition Competition (ILSVRC) took place, most of the image recognition techniques have been replaced by deep learning. Hence, it is not surprising that deep learning also dominates the field of pathological image analysis. The state of the art of machine learning approaches for histopathological image analysis was recently reviewed by Komura and Ishikawa [97]. Several algorithms have recently been developed and reported to perform similar to or better than human pathologists in their respective domain [98-100]. Despite all of these advancements in the field of digital pathology, many pathology departments still maintain the use of physical slides and continue to use manual annotation of clinical tissue samples.

With routine MSI pixel sizes of around $50 \mu \mathrm{m}$, annotation for MSI purposes has likewise been performed rather coarsely, where regions of interest had diameters of hundreds of micrometers, which is a full order of magnitude lower than what is detected in optical images. As the spatial resolution of MSI moves towards the single cell scale, manual annotation will become impractical especially in the clinical setting where hundreds of samples need to be annotated per day. Hence, digital pathology image analysis will be necessary to ensure that a high level of detail is preserved in the image when co-registered with MSI datasets. In the MSI community, the use of digital pathology image analysis for annotations of the MSI-analyzed and H\&E stained tissue sections has not yet been reported as of the writing of this review article. Figure 8 demonstrates the potential that MSI has when combined with digital image analysis.

\section{MSI and systems biology}

Data analysis in the MALDI-MSI workflow also requires assigning the detected mass-to-charge $(\mathrm{m} / \mathrm{z})$ values of interest to a molecular identity (ID) for further systematic analysis. Confident ID assignment should be based on high mass accuracy and a matching MS/MS fragmentation spectrum. Until recently, the majority of this work was done manually and was time consuming. Recently, a new application of data dependent acquisition (DDA)

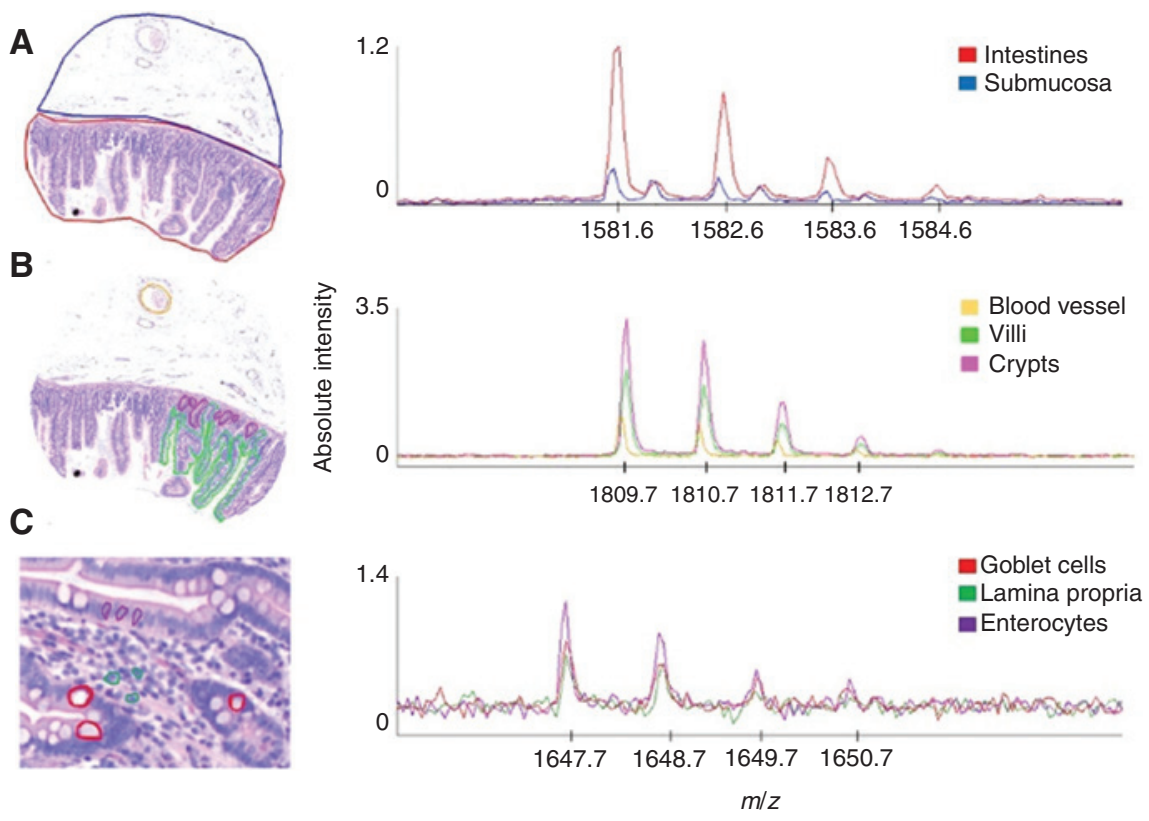

Figure 8: The need for detailed histopathological annotations in high-resolution MALDI-MSI. This is exemplified by different levels of annotations in a H\&E stain from a tissue core biopsy of human small intestine tissue and the corresponding MALDI-MSI data of the defined regions. All annotations were done manually for demonstration purposes. (A) Coarse annotation of the largest tissue components and the respective average MS signal for several $\mathrm{m} / \mathrm{z}$ values belonging to these regions. (B) More detailed annotation of the major histological features and the respective average MS signal for several $\mathrm{m} / \mathrm{z}$ values belonging to blood vessel, villi, and crypts. (C) Single cell annotation of a few cell types and the respective average MS signal for several $m / z$ values belonging to these cells. 
methodology for MALDI-MSI [101-103] along with new software [104] that can match the precursor ion mass with the corresponding accumulated MS/MS spectra has provided an automatic and scalable method of ID assignment. Furthermore, novel protocols have been developed, including the work of Paine et al. [105] who coupled ozone-induced dissociation to MALDI-MSI, enabling differential imaging of isomeric lipid species and lipid identification at the level of double-bond and sn-position of fatty acids. Likewise, an increase in the use of MSI instrumentation that provides high mass resolution and accuracy has expanded the ability of confidently assigning detected $m / z$ values to distinct molecular species [41, 106-108]. Next to that, platforms such as METASPACE $[106,109]$ provide identification pipelines that encourage researchers to upload their MSI data to create a large database that contains datasets from a variety of different platforms, diseases and research laboratories for community-based comparisons and identifications. Lastly, complementary analytical tools are also being integrated in the MSI workflows to increase identification capabilities and confidence [110-112].

In spite of recent developments of novel protocols and automatic ID assignment, the number of identified molecules from an MSI experiment remains relatively low compared to the number of actually detected $\mathrm{m} / z$ species. These limited identification capabilities are well illustrated in the studies by Minerva et al. [113] and Ščupáková et al. [114]. Minerva et al. [113], in a study focused on obesity, identified 46 out of 136 detected peptides by MALDI-MSI. Ščupáková et al. [114] investigated hepatic lipid profiles by MALDI-MSI in a cohort of non-alcoholic fatty liver disease patients and identified 86 lipid species out of the 546 detected $\mathrm{m} / \mathrm{z}^{\prime} \mathrm{s}$ of interest. These exemplary studies show the need for further developments to bridge this gap between detection and identification.

Another challenge is the integration of molecular information from various high-throughput platforms, for example, transcriptomics, with MSI datasets. Few studies have attempted to combine MALDI-MSI data with gene expression data to further validate their findings, for instance, Ščupáková et al. [114] combined lipid MALDI-MSI with mRNA sequencing gene expression datasets. However, there is ample room for expanding the type of data included in the analysis, as well as data interpretation. The main issue often is the relatively large differences between the level of information (resolution) and the content (biological meaning) that one platform offers vs. the other. This does not make these datasets conflicting, but rather highlights that more work is needed to properly integrate them to maximize the amount of information obtained from multiple types of datasets.

Other fields, such as transcriptomics $[115,116]$ and proteomics [117], are also working towards collecting single cell-based information in a spatially resolved manner. Concurrently, online resources are being curated to match these advancements to share and catalog data. One wellknown example is the Human Protein Atlas [118, 119], which collects protein specific information and their locations in various organs. Another database, the Allen Brain Atlas [120] and its platform BrainScope [121], are available for visualization of both anatomical data as well as genespecific data across developmental time periods of the human brain. MSI datasets have already been spatially registered to these resources for automated use of annotations and molecular information for the investigation of brain-related diseases such as depression and migraine [76, 77, 122-124]. Such co-registration allows for direct interpretation of MSI, magnetic resonance imaging and immunohistochemistry data in one view, and therefore also contributes to the utilization of those atlases.

Newer platforms are also available, such as the Single Cell Expression Atlas [125-127] which integrates gene expression data from single cells, and Cytosplore [128] which utilizes mass cytometry data to build a visual analysis of the immune system. Finally, the Human Cell Atlas [129] was developed with the vision of systematically creating comprehensive reference maps of all human cells. All of these databases are working towards mapping biological systems at various levels by integrating various types of data. One can envision that with appropriate spatial resolution, MSI datasets could contribute immensely to these databases to increase our molecular knowledge and understanding of biological systems while spatially preserving cellular and tissue architecture.

\section{Conclusions}

MALDI-MSI has emerged as a powerful research tool for tissue-based biomedical research questions that require spatially resolved molecular analysis. Recent advances in sample preparation, instrumentation and data processing have led the MALDI-MSI field to approach single cell resolution. Further developments in laser and detector technologies are necessary to reach cellular (and perhaps even subcellular) scales required for imaging clinical samples. These developments need to be complemented by advanced computational solutions, which include digital image analysis, co-registration, super-resolution algorithms and integration with other molecular omics data 
to fully exploit these data. In order to achieve this integration, these other omics techniques need to reach higher spatial resolution. Meanwhile, the MALDI-MSI field must work toward achieving higher molecular coverage. Such future technology developments, in conjunction with the development of integrative molecular single cell databases across various biological levels and spatial resolutions will allow us to deepen our understanding of human health.

Acknowledgments: The authors thank Marta MartinLorenzo, PhD (M4I Institute, Maastricht) for kindly providing data for Fig. 1A, the BRIC institute for providing tissue samples for Fig. 3A, and Janssen Pharmaceutica NV for providing tissue samples as well as Lennart Huizing for data acquisition for Fig. 5B.

[Correction added after online publication 27 February 2020: The sentence "The authors thank Marta Martin-Lorenzo, PhD (M4I Institute, Maastricht) for kindly providing data for Figure 1A and Janssen Pharmaceutica NV for providing data for Figure 5B." was updated to "The authors thank Marta Martin-Lorenzo, PhD (M4I Institute, Maastricht) for kindly providing data for Fig. 1A, the BRIC institute for providing tissue samples for Fig. 3A, and Janssen Pharmaceutica NV for providing tissue samples as well as Lennart Huizing for data acquisition for Fig. 5B.”]

Author contributions: All the authors have accepted responsibility for the entire content of this submitted manuscript and approved submission.

Research funding: This work was financially supported by the Dutch province of Limburg as part of the "LINK" program, as well as funding from the National Institutes of Health (NIH) of the United States of America, i.e. NIH R01 CA213428, Funder Id: http://dx.doi. org/10.13039/100000009, R01 CA213492-01A1 and T32 CA193145. BB acknowledges the financial support of the European Union (ERA-NET TRANSCAN 2; Grant No. 643638, Funder Id: http://dx.doi.org/10.13039/100010661). Employment or leadership: None declared.

Honorarium: None declared.

Competing interests: The funding organization(s) played no role in the study design; in the collection, analysis, and interpretation of data; in the writing of the report; or in the decision to submit the report for publication.

\section{References}

1. Contents of Essentials of Cell Biology | Learn Science at Scitable. https://www.nature.com/scitable/ebooks/essentials-of-cellbiology-14749010/118238537. Accessed: 26 Jul 2019.
2. Zhu J, Thompson CB. Metabolic regulation of cell growth and proliferation. Nat Rev Mol Cell Biol 2019;20:436-50.

3. Uings IJ, Farrow SN. Cell receptors and cell signalling. Mol Pathol 2000;53:295-9.

4. Manning AT, Garvin JT, Shahbazi RI, Miller N, McNeill RE, Kerin MJ. Molecular profiling techniques and bioinformatics in cancer research. Eur J Surg Oncol J Eur Soc Surg Oncol Br Assoc Surg Oncol 2007;33:255-65.

5. Ginzberg MB, Kafri R, Kirschner M. Cell biology. On being the right (cell) size. Science 2015;348:1245075.

6. Gillooly JF, Hein A, Damiani R. Nuclear DNA content varies with cell size across human cell types. Cold Spring Harb Perspect Biol 2015;7:a019091.

7. Philips RM\& R. How big is a human cell? http://book.bionumbers.org/how-big-is-a-human-cell/. Accessed: 26 Jul 2019.

8. Majno G, Joris I. Cells, tissues, and disease: principles of general pathology. Oxford: Oxford University Press, 2004.

9. Stern AD, Rahman AH, Birtwistle MR. Cell size assays for mass cytometry. Cytom Part J Int Soc Anal Cytol 2017;91:14-24.

10. Gerdes MJ, Sevinsky CJ, Sood A, Adak S, Bello MO, Bordwell A, et al. Highly multiplexed single-cell analysis of formalinfixed, paraffin-embedded cancer tissue. Proc Natl Acad Sci USA 2013;110:11982-7.

11. Clarke GM, Zubovits JT, Shaikh KA, Wang D, Dinn SR, Corwin AD, et al. A novel, automated technology for multiplex biomarker imaging and application to breast cancer. Histopathology 2014;64:242-55.

12. Gown AM. Diagnostic immunohistochemistry: what can go wrong and how to prevent it. Arch Pathol Lab Med 2016;140:893-8.

13. Chaurand P, Schwartz SA, Reyzer ML, Caprioli RM. Imaging mass spectrometry: principles and potentials. Toxicol Pathol 2005;33:92-101.

14. Chughtai K, Heeren RM. Mass spectrometric imaging for biomedical tissue analysis. Chem Rev 2010;110:3237-77.

15. Vaysse P-M, Heeren RM, Porta T, Balluff B. Mass spectrometry imaging for clinical research - latest developments, applications, and current limitations. The Analyst 2017;142:2690-712.

16. Swales JG, Hamm G, Clench MR, Goodwin RJ. Mass spectrometry imaging and its application in pharmaceutical research and development: a concise review. Int J Mass Spectrom 2019;437:99-112.

17. Deininger S-O, Ebert MP, Fütterer A, Gerhard M, Röcken C. MALDI imaging combined with hierarchical clustering as a new tool for the interpretation of complex human cancers. J Proteome Res 2008;7:5230-6.

18. Kriegsmann J, Kriegsmann M, Casadonte R. MALDI TOF imaging mass spectrometry in clinical pathology: a valuable tool for cancer diagnostics (Review). Int J Oncol 2015;46:893-906.

19. Michno W, Wehrli PM, Blennow K, Zetterberg H, Hanrieder J. Molecular imaging mass spectrometry for probing protein dynamics in neurodegenerative disease pathology. J Neurochem 2018. doi: 10.1111/jnc.14559.

20. Clark AR, Calligaris D, Regan MS, Pomeranz Krummel D, Agar JN, Kallay L, et al. Rapid discrimination of pediatric brain tumors by mass spectrometry imaging. J Neurooncol 2018;140:269-79.

21. Piga I, Capitoli G, Denti V, Tettamanti S, Smith A, Stella M, et al. The management of haemoglobin interference for the MALDIMSI proteomics analysis of thyroid fine needle aspiration biopsies. Anal Bioanal Chem 2019;411:5007-12. 
22. Casadonte R, Kriegsmann M, Perren A, Baretton G, Deininger S-O, Kriegsmann K, et al. Development of a class prediction model to discriminate pancreatic ductal adenocarcinoma from pancreatic neuroendocrine tumor by MALDI mass spectrometry imaging. Proteomics Clin Appl 2019;13:e1800046.

23. Aichler M, Borgmann D, Krumsiek J, Buck A, MacDonald PE, Fox JE, et al. $\mathrm{N}$-acyl taurines and acylcarnitines cause an imbalance in insulin synthesis and secretion provoking $\beta$ cell dysfunction in type 2 diabetes. Cell Metab 2017;25:1334-47.e4.

24. Heeren RM. Getting the picture: the coming of age of imaging MS. Int J Mass Spectrom 2015;377:672-80.

25. Angelo M, Bendall SC, Finck R, Hale MB, Hitzman C, Borowsky $A D$, et al. Multiplexed ion beam imaging of human breast tumors. Nat Med 2014;20:436-42.

26. Caprioli RM, Farmer TB, Gile J. Molecular imaging of biological samples: localization of peptides and proteins using MALDI-TOF MS. Anal Chem 1997;69:4751-60.

27. Buchberger AR, DeLaney K, Johnson J, Li L. Mass spectrometry imaging: a review of emerging advancements and future insights. Anal Chem 2018;90:240-65.

28. Kompauer M, Heiles S, Spengler B. Atmospheric pressure MALDI mass spectrometry imaging of tissues and cells at $1.4-\mu \mathrm{m}$ lateral resolution. Nat Methods 2017;14:90-6.

29. Dueñas ME, Essner JJ, Lee YJ. 3D MALDI Mass spectrometry imaging of a single cell: spatial mapping of lipids in the embryonic development of zebrafish. Sci Rep 2017;7:14946.

30. Feenstra AD, Dueñas ME, Lee YJ. Five micron high resolution MALDI mass spectrometry imaging with simple, interchangeable, multi-resolution optical system. J Am Soc Mass Spectrom 2017;28:434-42.

31. Korte AR, Yandeau-Nelson MD, Nikolau BJ, Lee YJ. Subcellularlevel resolution MALDI-MS imaging of maize leaf metabolites by MALDI-linear ion trap-Orbitrap mass spectrometer. Anal Bioanal Chem 2015;407:2301-9.

32. Dueñas ME, Klein AT, Alexander LE, Yandeau-Nelson MD, Nikolau $B J$, Lee YJ. High spatial resolution mass spectrometry imaging reveals the genetically programmed, developmental modification of the distribution of thylakoid membrane lipids among individual cells of maize leaf. Plant J 2017;89:825-38.

33. rapifleX MALDI Tissuetyper | MALDI Imaging re-defined. Bruker. com. https://www.bruker.com/products/mass-spectrometryand-separations/maldi-toftof/rapiflex-maldi-tissuetyper/overview.html. Accessed: 4 Oct 2019.

34. Prentice BM, Caprioli RM. The need for speed in matrix-assisted laser desorption/ionization imaging mass spectrometry. Postdoc J J Postdr Res Postdr Aff 2016;4:3-13.

35. Spraggins JM, Rizzo DG, Moore JL, Noto MJ, Skaar EP, Caprioli RM. Next-generation technologies for spatial proteomics: integrating ultra-high speed MALDI-TOF and high mass resolution MALDI FTICR imaging mass spectrometry for protein analysis. Proteomics 2016;16:1678-89.

36. Goodwin RJ. Sample preparation for mass spectrometry imaging: small mistakes can lead to big consequences. J Proteomics 2012;75:4893-911.

37. Lemaire R, Wisztorski M, Desmons A, Tabet JC, Day R, Salzet $M$, et al. MALDI-MS direct tissue analysis of proteins: improving signal sensitivity using organic treatments. Anal Chem 2006;78:7145-53.

38. Lemaire R, Desmons A, Tabet JC, Day R, Salzet M, Fournier I. Direct analysis and MALDI imaging of formalin-fixed, paraffinembedded tissue sections. J Proteome Res 2007;6:1295-305.
39. Schwartz SA, Reyzer ML, Caprioli RM. Direct tissue analysis using matrix-assisted laser desorption/ionization mass spectrometry: practical aspects of sample preparation. J Mass Spectrom JMS 2003;38:699-708.

40. Grillo F, Pigozzi S, Ceriolo P, Calamaro P, Fiocca R, Mastracci L. Factors affecting immunoreactivity in long-term storage of formalin-fixed paraffin-embedded tissue sections. Histochem Cell Biol 2015;144:93-9.

41. Ly A, Buck A, Balluff B, Sun N, Gorzolka K, Feuchtinger A, et al. High-mass-resolution MALDI mass spectrometry imaging of metabolites from formalin-fixed paraffin-embedded tissue. Nat Protoc 2016;11:1428-43.

42. Ergin B, Meding S, Langer R, Kap M, Viertler C, Schott C, et al. Proteomic analysis of PAXgene-fixed tissues. J Proteome Res 2010;9:5188-96.

43. Urban C, Buck A, Siveke JT, Lordick F, Luber B, Walch A, et al. PAXgene fixation enables comprehensive metabolomic and proteomic analyses of tissue specimens by MALDI MSI. Biochim Biophys Acta Gen Subj 2018;1862:51-60.

44. Caldwell RL, Caprioli RM. Tissue profiling by mass spectrometry: a review of methodology and applications. Mol Cell Proteomics MCP 2005;4:394-401.

45. Nelson KA, Daniels GJ, Fournie JW, Hemmer MJ. Optimization of whole-body zebrafish sectioning methods for mass spectrometry imaging. J Biomol Tech JBT 2013;24:119-27.

46. Carter CL, Jones JW, Farese AM, MacVittie TJ, Kane MA. Inflationfixation method for lipidomic mapping of lung biopsies by matrix assisted laser desorption/ionization-mass spectrometry imaging. Anal Chem 2016;88:4788-94.

47. Gill EL, Yost RA, Vedam-Mai V, Garrett TJ. Precast gelatin-based molds for tissue embedding compatible with mass spectrometry imaging. Anal Chem 2017;89:576-80.

48. Crecelius AC, Cornett DS, Caprioli RM, Williams B, Dawant BM, Bodenheimer B. Three-dimensional visualization of protein expression in mouse brain structures using imaging mass spectrometry. J Am Soc Mass Spectrom 2005;16:1093-9.

49. Strohalm M, Strohalm J, Kaftan F, Krásný L, Volný M, Novák P, et al. Poly[N-(2-hydroxypropyl)methacrylamide]-based tissueembedding medium compatible with MALDI mass spectrometry imaging experiments. Anal Chem 2011;83:5458-62.

50. Debanne D, Campanac E, Bialowas A, Carlier E, Alcaraz G. Axon physiology. Physiol Rev 2011;91:555-602.

51. Cooper DC. Introduction to Neuroscience. https://books.google. $\mathrm{nl} /$ books?id=jXnkai44PxYC\&lpg=PP1\&pg=PA4\#v=onepage $\&$ q $\mathrm{f}=$ false. Accessed: 26 Jul 2019.

52. Huizing LR, Ellis SR, Beulen BW, Barré FP, Kwant PB, Vreeken $R J$, et al. Development and evaluation of matrix application techniques for high throughput mass spectrometry imaging of tissues in the clinic. Clin Mass Spectrom 2019;12:7-15.

53. Caughlin S, Park DH, Yeung KK-C, Cechetto DF, Whitehead SN. Sublimation of DAN Matrix for the detection and visualization of gangliosides in rat brain tissue for MALDI imaging mass spectrometry. J Vis Exp 2017;121:e55254.

54. Li B, Zhang Y, Ge J, Liu K, Li P. Sample preparation for mass spectrometry imaging of leaf tissues: a case study on analyte delocalization. Anal Bioanal Chem 2018;410:7449-56.

55. Anderson DM, Floyd KA, Barnes S, Clark JM, Clark JI, Mchaourab $\mathrm{H}$, et al. A method to prevent protein delocalization in imaging mass spectrometry of non-adherent tissues: application to small vertebrate lens imaging. Anal Bioanal Chem 2015;407:2311-20. 
56. Hankin JA, Barkley RM, Murphy RC. Sublimation as a method of matrix application for mass spectrometric imaging. J Am Soc Mass Spectrom 2007;18:1646-52.

57. Li S, Zhang Y, Liu J, Han J, Guan M, Yang H, et al. Electrospray deposition device used to precisely control the matrix crystal to improve the performance of MALDI MSI. Sci Rep 2016;6:37903.

58. Gemperline E, Rawson S, Li L. Optimization and comparison of multiple MALDI matrix application methods for small molecule mass spectrometric imaging. Anal Chem 2014;86:10030-5.

59. Yang J, Caprioli RM. Matrix sublimation/recrystallization for imaging proteins by mass spectrometry at high spatial resolution. Anal Chem 2011;83:5728-34.

60. Jaskolla TW, Karas M, Roth U, Steinert K, Menzel C, Reihs K. Comparison between vacuum sublimed matrices and conventional dried droplet preparation in MALDI-TOF mass spectrometry. J Am Soc Mass Spectrom 2009;20:1104-14.

61. Tang X, Huang L, Zhang W, Zhong H. Chemical imaging of latent fingerprints by mass spectrometry based on laser activated electron tunneling. Anal Chem 2015;87:2693-701.

62. Jurchen JC, Rubakhin SS, Sweedler JV. MALDI-MS imaging of features smaller than the size of the laser beam. J Am Soc Mass Spectrom 2005;16:1654-9.

63. Marko-Varga G, Fehniger TE, Rezeli M, Döme B, Laurell T, Végvári A. Drug localization in different lung cancer phenotypes by MALDI mass spectrometry imaging. J Proteomics 2011;74:982-92.

64. Chaurand P, Cornett DS, Angel PM, Caprioli RM. From wholebody sections down to cellular level, multiscale imaging of phospholipids by MALDI mass spectrometry. Mol Cell Proteomics MCP 2011;10:0110.004259.

65. Römpp A, Spengler B. Mass spectrometry imaging with high resolution in mass and space. Histochem Cell Biol 2013;139:759-83.

66. McDonnell LA, Heeren RM. Imaging mass spectrometry. Mass Spectrom Rev 2007;26:606-43.

67. Kompauer M, Heiles S, Spengler B. Autofocusing MALDI mass spectrometry imaging of tissue sections and 3D chemical topography of nonflat surfaces. Nat Methods 2017;14:1156-8.

68. Soltwisch J, Kettling H, Vens-Cappell S, Wiegelmann M, Müthing J, Dreisewerd K. Mass spectrometry imaging with laser-induced postionization. Science 2015;348:211-5.

69. Home. Medipix. 2017.https://medipix.web.cern.ch/node/1. Accessed: 26 Jul 2019.

70. Ballabriga R, Campbell M, Llopart X. ASIC developments for radiation imaging applications: the Medipix and Timepix family. Nucl Instrum Meth 2017;A878:10-23.

71. Jungmann JH, Heeren RM. Detection systems for mass spectrometry imaging: a perspective on novel developments with a focus on active pixel detectors. Rapid Commun Mass Spectrom 2013;27:1-23.

72. Potočnik NO, Porta T, Becker M, Heeren RM, Ellis SR. Use of advantageous, volatile matrices enabled by next-generation high-speed matrix-assisted laser desorption/ionization time-offlight imaging employing a scanning laser beam. Rapid Commun Mass Spectrom 2015;29:2195-203.

73. Spraggins JM, Caprioli RM. High-speed MALDI-TOF imaging mass spectrometry: rapid ion image acquisition and considerations for next generation instrumentation. J Am Soc Mass Spectrom 2011;22:1022-31.

74. Bosworth E, Li S, Vestal C, Mills G, Tseng A, Dahl M, et al. Highperformance MALDI-TOF imaging mass spectrometer. https:// www.simultof.com/index.php/posters-and-presentations/. Accessed: 26 Jul 2019.
75. Barré F, Rocha B, Dewez F, Towers M, Murray P, Claude E, et al. Faster raster matrix-assisted laser desorption/ionization mass spectrometry imaging of lipids at high lateral resolution. Int J Mass Spectrom 2019;437:38-48.

76. Abdelmoula WM, Carreira RJ, Shyti R, Balluff B, van Zeijl RJ, Tolner EA, et al. Automatic registration of mass spectrometry imaging data sets to the Allen brain atlas. Anal Chem 2014;86:3947-54.

77. Verbeeck N, Yang J, De Moor B, Caprioli RM, Waelkens E, Van de Plas R. Automated anatomical interpretation of ion distributions in tissue: linking imaging mass spectrometry to curated atlases. Anal Chem 2014;86:8974-82.

78. Abdelmoula WM, Škrášková K, Balluff B, Carreira RJ, Tolner $\mathrm{EA}$, Lelieveldt BP, et al. Automatic generic registration of mass spectrometry imaging data to histology using nonlinear stochastic embedding. Anal Chem 2014;86:9204-11.

79. Chen X, Zheng B, Liu H. Optical and digital microscopic imaging techniques and applications in pathology. Anal Cell Pathol Amst 2011;34:5.

80. Alexandrov T, Meding S, Trede D, Kobarg JH, Balluff B, Walch $A$, et al. Super-resolution segmentation of imaging mass spectrometry data: solving the issue of low lateral resolution. J Proteomics 2011;75:237-45.

81. McCombie G, Staab D, Stoeckli M, Knochenmuss R. Spatial and spectral correlations in MALDI mass spectrometry images by clustering and multivariate analysis. Anal Chem 2005;77:6118-24.

82. Walch A, Rauser S, Deininger S-O, Höfler H. MALDI imaging mass spectrometry for direct tissue analysis: a new frontier for molecular histology. Histochem Cell Biol 2008;130:421-34.

83. Alexandrov T, Becker M, Deininger S-O, Ernst G, Wehder L, Grasmair M, et al. Spatial segmentation of imaging mass spectrometry data with edge-preserving image denoising and clustering. J Proteome Res 2010;9:6535-46.

84. Van de Plas R, Yang J, Spraggins J, Caprioli RM. Image fusion of mass spectrometry and microscopy: a multimodality paradigm for molecular tissue mapping. Nat Methods 2015;12:366-72.

85. Ščupáková K, Terzopoulos V, Jain S, Smeets D, Heeren RM. A patch-based super resolution algorithm for improving image resolution in clinical mass spectrometry. Sci Rep 2019;9:2915.

86. Cassese A, Ellis SR, Ogrinc Potočnik N, Burgermeister E, Ebert $\mathrm{M}$, Walch $A$, et al. Spatial autocorrelation in mass spectrometry imaging. Anal Chem 2016;88:5871-8.

87. Rosai J. Why microscopy will remain a cornerstone of surgical pathology. Lab Investig J Tech Methods Pathol 2007;87:403-8.

88. Turk JL. Rudolf Virchow - father of cellular pathology. J R Soc Med 1993;86:688-9.

89. Elmore JG, Longton GM, Carney PA, Geller BM, Onega T, Tosteson AN, et al. Diagnostic concordance among pathologists interpreting breast biopsy specimens. J Am Med Assoc 2015;313:1122-32.

90. El-Badry AM, Breitenstein S, Jochum W, Washington K, Paradis V, Rubbia-Brandt L, et al. Assessment of hepatic steatosis by expert pathologists: the end of a gold standard. Ann Surg 2009;250:691-7.

91. Djuric U, Zadeh G, Aldape K, Diamandis P. Precision histology: how deep learning is poised to revitalize histomorphology for personalized cancer care. NPJ Precis Oncol 2017;1:22.

92. Pantanowitz L. Digital images and the future of digital pathology. J Pathol Inform 2010;1:15.

93. Spanhol FA, Oliveira LS, Petitjean C, Heutte L. Breast cancer histopathological image classification using Convolutional Neural 
Networks. In: 2016 International Joint Conference on Neural Networks (IJCNN). 2016;2560-7.

94. Mungle T, Tewary S, Das DK, Arun I, Basak B, Agarwal S, et al. MRF-ANN: a machine learning approach for automated ER scoring of breast cancer immunohistochemical images. J Microsc 2017;267:117-29.

95. Caie PD, Turnbull AK, Farrington SM, Oniscu A, Harrison DJ. Quantification of tumour budding, lymphatic vessel density and invasion through image analysis in colorectal cancer. J Transl Med 2014;12:156.

96. van Diest PJ, Huisman A, van Ekris J, Meijer J, Willems S, Hofhuis $\mathrm{H}$, et al. Pathology image exchange: the Dutch digital pathology platform for exchange of whole-slide images for efficient teleconsultation, telerevision, and virtual expert panels. JCO Clin Cancer Inform 2019;1-7.

97. Komura D, Ishikawa S. Machine learning methods for histopathological image analysis. Comput Struct Biotechnol J 2018;16:34-42.

98. Hou L, Samaras D, Kurc TM, Gao Y, Davis JE, Saltz JH. Patchbased convolutional neural network for whole slide tissue image classification. In: 2016 IEEE Conference on Computer Vision and Pattern Recognition (CVPR). 2016; 2424-2433.

99. Xu J, Luo X, Wang G, Gilmore H, Madabhushi A. A Deep Convolutional Neural Network for segmenting and classifying epithelial and stromal regions in histopathological images. Neurocomputing 2016;191:214-23.

100. Sheikhzadeh F, Ward RK, van Niekerk D, Guillaud M. Automatic labeling of molecular biomarkers of immunohistochemistry images using fully convolutional networks. PLoS One 2018;13:e0190783.

101. OuYang C, Chen B, Li L. High throughput in situ DDA analysis of neuropeptides by coupling novel multiplex mass spectrometric imaging (MSI) with gas phase fractionation. J Am Soc Mass Spectrom 2015;26:1992-2001.

102. Hansen RL, Lee YJ. High-spatial resolution mass spectrometry imaging: toward single cell metabolomics in plant tissues. Chem Rec 2018;18:65-77.

103. Ellis SR, Paine MR, Eijkel GB, Pauling JK, Husen P, Jervelund MW, et al. Automated, parallel mass spectrometry imaging and structural identification of lipids. Nat Methods 2018;15:515.

104. Lipostar MS. Mol. Horiz. //www.molhorizon.it/software/. Accessed: 1 Aug 2019.

105. Paine MR, Poad BL, Eijkel GB, Marshall DL, Blanksby SJ, Heeren $R M$, et al. Mass spectrometry imaging with isomeric resolution enabled by ozone-induced dissociation. Angew Chem 2018;130:10690-4.

106. Palmer A, Phapale P, Chernyavsky I, Lavigne R, Fay D, Tarasov $A$, et al. FDR-controlled metabolite annotation for high-resolution imaging mass spectrometry. Nat Methods 2017;14:57-60.

107. Heijs B, Carreira RJ, Tolner EA, de Ru AH, van den Maagdenberg $A M$, van Veelen PA, et al. Comprehensive analysis of the mouse brain proteome sampled in mass spectrometry imaging. Anal Chem 2015;87:1867-75.

108. Black AP, Liang H, West CA, Wang M, Herrera HP, Haab BB, et al. A novel mass spectrometry platform for multiplexed $\mathrm{N}$-Glycoprotein biomarker discovery from patient biofluids by antibody panel based N-Glycan imaging. Anal Chem 2019;91:8429-35.

109. METASPACE annotation platform. https://metaspace2020.eu/. Accessed: 26 Jul 2019.
110. Théron L, Centeno D, Coudy-Gandilhon C, Pujos-Guillot E, Astruc $\mathrm{T}$, Rémond D, et al. A proof of concept to bridge the gap between mass spectrometry imaging, protein identification and relative quantitation: MSI-LC-MS/MS-LF. Proteomes 2016;4:32.

111. Dilillo M, Pellegrini D, Ait-Belkacem R, de Graaf EL, Caleo M, McDonnell LA. Mass spectrometry imaging, laser capture microdissection, and LC-MS/MS of the same tissue section. J Proteome Res 2017;16:2993-3001.

112. Lamont L, Baumert M, Ogrinc Potočnik N, Allen M, Vreeken $R$, Heeren RM, et al. Integration of ion mobility MSE after fully automated, online, high-resolution liquid extraction surface analysis micro-liquid chromatography. Anal Chem 2017;89:11143-50.

113. Minerva L, Boonen K, Menschaert G, Landuyt B, Baggerman G, Arckens $L$. Linking mass spectrometric imaging and traditional peptidomics: a validation in the obese mouse model. Anal Chem 2011;83:7682-91.

114. Ščupáková K, Soons Z, Ertaylan G, Pierzchalski KA, Eijkel GB, Ellis SR, et al. Spatial systems lipidomics reveals nonalcoholic fatty liver disease heterogeneity. Anal Chem 2018;90:5130-5138.

115. Ståhl PL, Salmén F, Vickovic S, Lundmark A, Navarro JF, Magnusson J, et al. Visualization and analysis of gene expression in tissue sections by spatial transcriptomics. Science 2016;353:78-82.

116. Reeves JW, Zhang Z, Norgaard ZK, Zhou DM, Gong J, Liang Y, et al. Defining the microenvironment landscape of bladder cancer using highly multiplexed spatial genomic and proteomic analysis. Cancer Biol 2019;675926.

117. Doll S, Dreßen M, Geyer PE, Itzhak DN, Braun C, Doppler SA, et al. Region and cell-type resolved quantitative proteomic map of the human heart. Nat Commun 2017;8:1-13.

118. The Human Protein Atlas. https://www.proteinatlas.org/. Accessed: 26 Jul 2019.

119. Uhlén M, Fagerberg L, Hallström BM, Lindskog C, Oksvold P, Mardinoglu A, et al. Proteomics. Tissue-based map of the human proteome. Science 2015;347:1260419.

120. Hawrylycz MJ, Lein ES, Guillozet-Bongaarts AL, Shen EH, Ng L, Miller JA, et al. An anatomically comprehensive atlas of the adult human brain transcriptome. Nature 2012;489:391-9.

121. Huisman SM, van Lew B, Mahfouz A, Pezzotti N, Höllt T, Michielsen L, et al. BrainScope: interactive visual exploration of the spatial and temporal human brain transcriptome. Nucleic Acids Res 2017;45:e83-e83.

122. Carreira RJ, Shyti R, Balluff B, Abdelmoula WM, van Heiningen $\mathrm{SH}$, van Zeijl RJ, et al. Large-scale mass spectrometry imaging investigation of consequences of cortical spreading depression in a transgenic mouse model of migraine. J Am Soc Mass Spectrom 2015;26:853-61.

123. Škrášková K, Khmelinskii A, Abdelmoula WM, De Munter S, Baes M, McDonnell L, et al. Precise anatomic localization of accumulated lipids in Mfp2 deficient murine brains through automated registration of SIMS images to the Allen brain Atlas. J Am Soc Mass Spectrom 2015;26:948-57.

124. Verbeeck N, Spraggins JM, Murphy MJ, Wang H-D, Deutch AY, Caprioli RM, et al. Connecting imaging mass spectrometry and magnetic resonance imaging-based anatomical atlases for automated anatomical interpretation and differential analysis. Biochim Biophys Acta Proteins Proteomics 2017;1865:967-77.

125. Home < Single Cell Expression Atlas < EMBL-EBI. https://www. ebi.ac.uk/gxa/sc/home. Accessed: 26 Jul 2019. 
126. Howick VM, Russell A, Andrews T, Heaton H, Reid AJ, Natarajan $\mathrm{KN}$, et al. the malaria cell atlas: a comprehensive reference of single parasite transcriptomes across the complete Plasmodium life cycle. bioRxiv 2019;527556. https://www.biorxiv.org/ content/10.1101/527556v1.

127. Polański K, Young MD, Miao Z, Meyer KB, Teichmann SA, Park J-E. BBKNN: fast batch alignment of single cell transcriptomes.
Bioinformatics 2019;1-2. https://doi.org/10.1093/bioinformatics/btz625/5545955.

128. Höllt T, Pezzotti N, van Unen V, Koning F, Eisemann E, Lelieveldt $\mathrm{B}$, et al. Cytosplore: interactive immune cell phenotyping for large single-cell datasets. Comput Graph Forum 2016;35:171-80. 129. Regev A, Teichmann SA, Lander ES, Amit I, Benoist C, Birney E, et al. The Human Cell Atlas. eLife 2017;6. 